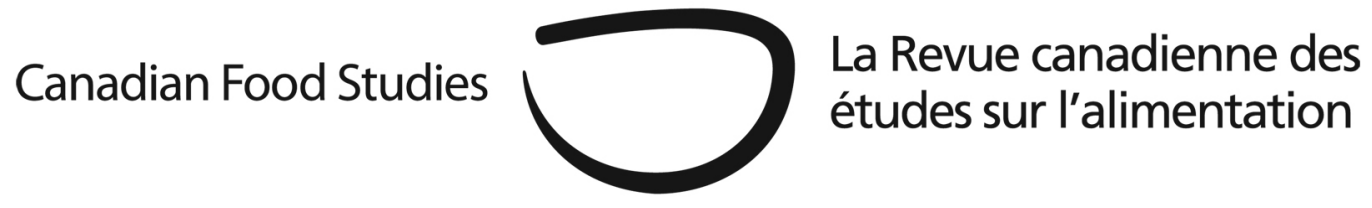

\author{
Original Research Article
}

\title{
Faux-meat and masculinity: The gendering of food on three vegan blogs
}

Dana Hart

\begin{abstract}
This study explores the relationship between gender and veganism through a critical analysis of food-based discourse on three vegan blogs. As many researchers note, there is a strong association between meat and masculinity in North American society (Nath, 2011; Rothgerber, 2013; Rozin, Hormes, Faith \& Wansink, 2012; Ruby \& Heine, 2011; Sumpter, 2015). While some researchers argue that the practice of veganism inherently challenges traditional gender norms (Adams, 2015; Potts and Parry, 2010), in these blog posts there is little room for alternative gender performativity. Drawing upon critical feminist and vegan studies literature, and previous discourse analysis of food blogs, this research examines the intersections of gender and food through the practice of veganism. Furthermore, it analyses how the association between meat and masculinity is applied in the gendering of vegan food. I argue that the gendered discourse of vegan food on these blogs reinforces, rather than challenges, traditional gender norms through the use of tropes describing "carnivorous men" and "manly meals” with hopes of satiating male appetites.
\end{abstract}

Keywords: veganism; gender; meat; masculinity; blogs 


\section{Introduction}

"No, no, no. The steak is for her; I ordered the butternut squash quiche" (Coret, 2014).

If North Americans adhered to the gender norms that our pricey television advertisements banked on, men would only consume steak, burgers, ribs and beer, while women would nibble on salads, fruit, and probiotic yogurt; however, this is not the case. Why are certain foods considered appropriate for certain genders, and how are these norms reinforced or challenged? According to Butler (1988), gender is not an inherent, static quality of an individual, so it must be repeatedly constructed through action and language. Likewise, West and Zimmerman (1987) argue that binary gender categories are generally applied through tests in daily interactions to assign the gender category that seems appropriate. Food consumption is one test through which gender identity, norms, and hierarchy can be defined, reinforced, or challenged (Adams, 2015). In this paper, I examine the ways in which gender performance occurs through the discussion of food on vegan blogs.

While some have argued the practice of veganism has the potential to challenge hegemonic meat-eating norms of masculinity (Adams, 2015; Potts \& Parry, 2010; Wright, 2015), I will demonstrate that vegan food is masculinized on three North American vegan blogs using discourse identical to normative meat-eating masculinity. Men on the blogs are described as carnivores that need to be convinced or deceived to eat vegan food. Certain foods are also specifically identified on the blogs as appropriate for men, and are described as being "hearty" or "meaty" enough to satisfy male appetites. The blog posts and comments demonstrate a strong effort to convince men to eat vegan food, especially through traditionally meat-based meals, and prevalent emotional and food labour to balance the healthiness of what men eat with the needs of their "carnivorous" appetites.

\section{Literature review}

\section{Meat and masculinity}

"Gender construction includes instruction about appropriate foods. Being a man in [Western] culture is tied to identities that they either claim or disown - what 'real' mean do and don't do. 'Real' men don't eat quiche. It's not only an issue of privilege, it's an issue of symbolism. Manhood is constructed in [Western] culture, in part, by access to meat eating and control of other bodies" (Adams, 2015, p. xxvii).

There is a strong relationship between meat and masculinity in Western cultures. Many authors argue that the symbolism between meat and masculinity stems from hegemonic ideals of masculinity embodied in the narrative of man as hunter, hunting to provide for their families 
while the women and children remain at home to forage (Gelfer, 2013; Nath, 2011; Rozin, Hormes, Faith \& Wansink,, 2012; Sobal, 2005; Sumpter, 2015). In archaeological and anthropological studies on early hunter-gatherer societies, an androcentric sexual division of labour between hunting and gathering was the favoured model for understanding pre-historic food acquisition (Geller, 2009). Hunting to procure meat was constructed as a male dominated activity and therefore became strongly associated with masculinity (Rozin et al, 2012). Despite the heterogeneous methods of food acquisition and gendered divisions of labour in past and present gathering and hunting societies, the idea of "man the hunter" is still perpetuated today in Western understandings of masculinity and provision, and can be seen, for example, in the cliché of "bringing home the bacon" (Sobal, 2005).

Eating meat is also considered essential for acquiring the strength needed for "masculine" activities, such as playing football (Brady \& Ventresca, 2014). Although there are successful vegan football players, weight lifters, and athletes (Brady \& Ventresca, 2014; Greenebaum \& Dexter, 2017), traditional values of masculinity foster the notion that meat eating is necessary for strong, male bodies (Roos, Prättälä \& Koski, 2001), leading men who have plant-based diets to be perceived as weak and less masculine than their meat-eating counterparts (Ruby \& Heine, 2011). Roos et al. (2001) interviewed a sample of Finnish carpenters who were skeptical as to whether vegetables could be considered a proper meal. The carpenters refer to vegetables as "rabbit food" and believe that it is unhealthy to exclude meat from their diet for fear that they would lack the energy required for manual labour (Roos et al., 2001). Overall, the carpenters believe that the energy from meat is required to satisfy their "hearty appetites" (Roos et al., 2001, p. 53).

The portion size, presentation, and healthiness of meals have also been found to influence the gendering of food types. In a pilot study, Cavazza, Guidetti, and Butera (2015) identify hamburgers and Caprese salads as the most archetypal masculine and feminine foods, respectively. In addition to food type, they found that big portions were rated more masculine than small ones, and that food that is roughly presented is considered to be more masculine than elegantly presented food (Cavazza et al., 2015). Furthermore, Stein and Nemeroff (1995) found that individuals who consumed a "healthy" diet high in fruits, vegetables, whole-wheat bread, chicken, and potatoes were seen as less masculine than those who consumed "unhealthy" diets composed of red meat, french fries, donuts, and ice-cream. These large, messy, and unhealthy "masculine" meals are reflected in the large portioned, meat-centered Hungry Man brand dinners whose slogan is "Eat Like a Man” (Lutz, 2015) or the Manwich brand sauce for ground beef sandwiches whose slogan is "A sandwich is a sandwich, but a Manwich is a meal” (Hopkins, 2012).

\section{Critical feminist analysis of food blogs}

Since food consumption is a practice by which gender is performed in relation to culturally approved food type, portion, labour, and presentation (Thomas, 2016; Turner, Ferguson, Craig, 
Jeffries, \& Beaton, 2013), food blogs offer a discursive space where gender norms around food, appetite, and labour can be reproduced, modified, or challenged. Food bloggers share their personal life and food experiences (Boepple \& Thompson, 2014) and engage in an interactive community (Lynch, 2010) where readers are encouraged to participate and share their own experiences (Salvio, 2012). The limited studies that focus on gender performativity in food blogs have found that food blogging communities are highly female-dominated (Boepple \& Thompson, 2014; Dejmanee, 2016; Lynch, 2010; Salvio, 2012), and that traditional gender norms around food and labour are often reproduced in blogs (Dejmanee, 2016; Salvio, 2012). Salvio (2012) argues that food blogs offer a window into “contemporary domestic culture” (p. 32). However, while bringing domesticity into the public and professional sphere transgresses the traditionally gendered division between spheres of labour, Salvio (2012) found that discourse on the blogs "suggests little critical questioning about women, domestic life, and feminist identities” (p. 38). Dejmanee (2016) agrees, and finds that the potential "empowering entrepreneurialism" offered by professional blogging is undermined by the reproduction of a "conservative, hegemonic femininity" that is required for success in the food blogging community (p. 15).

Salvio (2012), Dejmanee (2016), and Lynch (2010) note that traditional gender norms are further reproduced in the discussions of gender-appropriate food. Salvio (2012) found that solidarity in the food community is based on distinctions between gendered "tastes" that "systematically privilege male power" (p. 34), specifically in regards to red meat. They write:

"Rare red meat and food that 'sticks to the ribs' were believed to be a sure route to satisfying the appetites of men. Women, on the other hand, craved dainty, decorative foods such as cucumber tea sandwiches and pink-frosted sugar cookies” (Salvio, 2012, p. 34-35). Dejmanee (2016) notes the significance of "gender reveal cakes," in which the center of a cake is filled with either blue or pink candies to indicate the sex of unborn babies, thus actively reproducing a colour-coded gender binary. Furthermore, in a study of a photography-based food blogging community, Lynch (2010) found that the food bloggers compare the portions and healthiness of their meals with that of their husbands. For example, the bloggers shared photos of their "sliver" of pizza next to their husband's larger piece, or their small portion of bread next to their husband's "mountain" of bread (Lynch, 2010, p. 326). While the studies to date offer some valuable findings, all of the authors stress the potential for further research into online food blogging communities. This explorative case study contributes to this body of feminist food blog analysis, but with a specific focus on the vegan food blogging community.

\section{Gender and veganism}

In this section I review some of the studies that have examined gendered practices of veganism, and ask whether practicing veganism provides an opportunity to challenge traditional gender expectations around what food is considered appropriate for men. According to Johnson (2011), a notable feature of vegan demographics in North America is that they are primarily female. 
Maurer (2002) suggests that it is likely the perceived femininity of avoiding meat that deters men from adopting the diet (p. 8). This makes sense, as studies have shown that vegetarians are perceived to be weaker and less masculine than omnivores (Minson \& Monin, 2012; Rothgerber, 2013; Rozin et al., 2012; Ruby \& Heine, 2011). However, this perception may be shifting. A recent study by Thomas (2016) examined the effects that diet has on perceptions of a individual's masculinity and found that omnivorous participants did not rate fictional male or female vegetarian characters as less masculine than omnivorous ones, but did rate vegan characters as less masculine than omnivorous ones. Furthermore, vegan characters were rated less masculine if they were vegan for personal beliefs, than if they were vegan for health reasons (Thomas, 2016). This suggests that choosing to be vegan for an external cause is considered to be more in opposition to traditional values of masculinity than adopting a vegan diet out of concern for one's personal health. Furthermore, the finding that vegetarian characters were not considered less masculine but the vegan characters were suggests that vegetarian diets (those without meat that do include other animal products) are becoming less gender defiant for men in North America, while veganism (a diet that contains no animal products, such as meat, fish, dairy, or eggs) remains less well known and further removed from the hegemonic ideal of omnivorous diets for men (Thomas, 2016).

The question remains: does veganism inherently challenge the meat-centred norms of traditional masculinity? Some research suggests that it does, while others find that through hybrid masculinities, veganism can be practiced in such a way as to reproduce hegemonic masculinity. Adams (2015) argues that eliminating the consumption of animal products from one's diet challenges the patriarchal notion that meat is required for strong (male) bodies. Wright (2015) agrees, and suggests that this is because “...men have more to lose by challenging standard dietary options than do women” (p. 108). Potts and Parry (2010) came to a similar conclusion through their examination of violent responses to a study on ethical consumption which stated that vegans may have a stronger sexual preference for people that share similar ethical beliefs. Potts and Parry (2010) argue that the aggressive backlash from omnivorous men who label vegans as “(sexual) losers, cowards, deviants, failures, and bigots” suggests that having sexual preferences based on the absence of meat eating "radically challenges the powerful links between meat-eating, masculinity and virility in western societies” (p. 53). For example, commenters on the American radio talk show website RonFez.net wrote: "I can't date a girl who won't put sausage in her mouth” while another on American opinion site Salon.com described vegans as "bitter, unhappy and morbid people [who] possess a paralyzing inability to give or receive love” (as cited in Potts \& Parry, 2010, p. 60). Other men in this study described ways that they would like to sexually consume, rape, or kill vegans, especially those who are female (Potts \& Parry, 2010). Potts and Parry (2010) argue that these responses are "entirely consistent with the role meat plays in constructions of masculine sexuality in western culture" (p. 64).

However, other studies argue that vegetarian and vegan practices can also promote the aggression and domination encouraged by traditional masculinity. Irvine (2015) argues that 
vegetarian masculinities both reproduce and challenge traditional masculinity in contextually specific ways. They argue that while eating meat is a practice that naturalizes normative masculinity, both omnivorous and vegetarian men engage in similar discourses of traditional masculinity (Irvine, 2015, p. 36). Johnson (2011) came to a similar conclusion by examining masculinity as conveyed in two books that promote veganism for men. Through a feminist content analysis of these two books (Skinny Bastard: A Kick-in-the-Ass for Real Men Who Want to Stop Being Fat and Start Getting Buff by Freedman and Barnouin (2009), and Meat is for Pussies: A How-to-Guide for Dudes Who Want to Get Fit, Kick Ass and Take Names by Joseph (2010)), Johnson (2011) argues that men often choose to become vegan within traditional constructs of masculinity and that vegan marketing directed towards men still employs traditional masculine ideologies. Johnson (2011) proposes that these two books draw upon ideas of traditional masculinity while advocating for a diet that eliminates meat consumption because they both promote the adoption of a vegan diet for reasons of personal health and fitness. While both books discuss health as the main motivator behind adopting a vegan diet, and also advocate veganism for environmental reasons, Johnson (2011) points out that they make minimal connections to animal rights. Instead, Johnson (2011) argues that a vegan diet motivated by empathy and compassion for other animals is discouraged by most masculinities, as traditional masculinities promote aggression and self-interest. The gendering of motivations for adopting a vegan diet is also supported by Thomas' (2016) findings discussed above, that fictional characters who adopted veganism for personal reasons were rated less masculine than those who became vegan for health reasons.

A recent study by Greenebaum and Dexter (2017) is the most comprehensive study todate on the gendering of male vegan practices. The authors interviewed twenty vegan men to see how masculinity is negotiated in their practices of veganism. They found that the interviewees displayed a sort of hybrid masculinity by “modifying values associated with veganism and femininity to align with traditional masculine standards” (Greenebaum \& Dexter, 2017). Furthermore, they found that this practice served to "actively challenge and reinforce hegemonic ideals of manhood” (Greenebaum \& Dexter, 2017). Similarly to "Hegans,” the macho, empowered male vegans described by Wright (2015), Greenebaum and Dexter (2017) found that "Veganism... strengthened [the men's] sense of self, and in effect, reinforced their masculinity" (p. 7). Furthermore, the vegan men said that increasing numbers of famous male vegan athletes were reducing the stigma of weakness associated with veganism, and were "living proof that one could retain a traditional sense of masculinity while opting out of meat and dairy" (Greenebaum \& Dexter, 2017, p. 7). While this challenges the link between meat and masculinity, it simultaneously reinforces the hegemonic values of strength and power valued by traditional masculinity. In conclusion, Greenebaum and Dexter (2017) argued that while the vegan men challenged the narrow definition of traditional masculinity, they also reproduced gender inequality in their discussion of how men legitimized the practice of veganism. 


\section{Methods}

For this preliminary research into how vegan food is discussed in gendered ways, I selected three vegan blogging websites with content composed of vegan recipes that also included some personal discussion in the blog posts. Blog websites were identified as an ideal data source to answer these research questions because they are public, easier to access than offline fieldwork methods which may require time and funding for travel and longer time in the field, and offer personal author and commenter narratives that can be analyzed (Snee, 2010). Although there are disadvantages to this method, discussed in the limitations below, the previous studies using food blogs discussed above have shown them to be a useful source of ethnographic data.

This research seeks to answer whether or not vegan foods are being discussed in gendered ways. It considers: whether certain foods are deemed appropriate for certain genders; whether the food is being discussed using gendered or gender non-specific language; if the food is associated with certain gender ideals; and whether there are any specific features of an ingredient or food dish that are being gendered. Based on these questions, I constructed the following criteria for selecting the blogs. First, it was important that the authors have been blogging in the vegan community for five or more years. Five was an arbitrarily chosen length of time, but was considered to be a legitimate amount of time for food practices to change (see food choice trajectories in Devine, Connors, Bisogni, Sobal, 1998), and for community building to occur within online vegan communities (Cherry, 2006). Second, a specific cultural region was chosen to facilitate cross-comparison between the blogs. According to Alexa.com (2016a), a website traffic counter that provides rankings based on data from the previous three months, the most popular vegan blogs appear to be from North America. Third, the website had to contain elements common to a blogging format, including dated entries, ability for readers to comment, and personal "diary” elements (Snee, 2010). A sample size of three blogs was determined to be appropriate to generate a comparative sample for this preliminary research. The final selection of blogs was chosen based on their content, structure and demographics. I chose the two most popular vegan blogs according to Alexa.com, however, since the most popular blogs were exclusively written by self-identified women, I included a male-authored vegan blog for gender diversity

The first website, Minimalist Baker, is run by an American “husband-wife team.” This blog was the most popular American vegan blog at the time of selection, according to Alexa.com (2016a). However, the wife of the pair, Dana, is the sole author of the selected blog posts. The second website, Oh She Glows, is run by Angela, a Canadian self-identified female, mother and wife who works at home running the website. Oh She Glows, was the second most popular vegan blog (Alexa.com, 2016b). The third website, Vegan Dad, whose name is not provided on the website and will therefore be referred to as Vegan Dad, is run by a Canadian father, husband, and university professor.

Next, I chose the twenty most recent blog posts from each website as of May 7, 2016. Posts included those posted that day to as far back as December 16, 2014. Based on the symbolic 
significance of meat to hegemonic masculinity in the standard North American diet, I used the search function of each site and the word "meat" to select five additional vegan "meat" themed posts per blog. These included recipes that would traditionally be animal-based but instead use a plant-based substitute such as lentil taco "meat" or chickpea "meatballs" for further comparison between omnivorous animal-based dishes and the exclusion of animal products in vegan meals.

A total of seventeen blog posts between the websites were excluded on the basis of lacking a recipe or diary type element to the post (for example, posts about giveaways, app releases, or site updates) ( $n=7)$, for containing only a recipe and no pretext $(n=6)$, for repetition of the same recipe on a site $(n=3)$, or a post about the "meat" of a coconut when searching for vegan versions of traditionally animal-based recipes $(n=1)$. Data collection continued until a total of twenty-five blog posts were chosen from each website. Therefore, a total of seventy-five blog posts from the three authors and their relevant comments were selected for analysis. The posts were collected and saved as PDF documents on May 7, 2016. They were then hand-coded and grouped into recurring themes based on the research questions outlined above.

\section{Limitations}

There are limitations to this study that need to be considered before the results are discussed. This study looks at three blog authors who present as white, middle class, adult, cis-gendered and heterosexual North American blog authors who, for leisure or self-employment, spend their time writing about food, testing recipes, and running a website. This means that there is narrow representation of experiences and perspectives from the authors of these websites. Another important limitation to note is that the data are collected both from the blogs' authors as well as the commenters on the blogs. It is important to remember when reading this discussion of blog posts and comments that, unless otherwise specified, the commenter is of unknown gender, sex, diet, race, ethnicity, geographic location, age, sexual orientation, or any other personal feature. This is because while the genders of the blog authors are mentioned on their websites, the genders of the commenters on the blog are often unknown, as they are solely marked with a selfchosen username and do not discuss themselves in the third person. However, it is also important to note that the commenters on the blogs are composed of overwhelmingly traditionally female names and the comments on the blogs almost exclusively discuss making food for male partners and family members. This finding will be discussed further in the results section. While it is a potential limitation that the identifiers provided may be falsified in an online context, this does not pose a significant threat on the basis that a similar risk is possible in any type of study, whether in person, via survey, or online (Hookway, 2008, p. 97). 


\section{About the vegan blogging community and selected blogs}

In the search for vegan blogs that would be suitable for this project there were gendered trends within the online vegan community that became apparent. Reading the "about" sections of a variety of vegan websites, the most glaring trend is the lack of male vegan bloggers in the blogging world. Self-identified women write all of the most popular North American vegan blogging sites I found, which was a common finding for other food blog researchers (Boepple \& Thompson, 2014; Dejmanee, 2016; Lynch, 2010; Salvio, 2012). Another significant difference is the style of blogs that the few male-run vegan blogs adopt. The majority of female run vegan blogs I found focus on similar themes of caring for family members, daily food work, and healthy living. The few popular male-run vegan blogs that I found, with the exception of Vegan Dad, focus solely on athleticism or are highly thematic such as Thug Kitchen (2016), Vegan Stoner (2016), or video blogs such as The Vegan Zombie (2016) or the Vegan Black Metal Chef (2016). The theme-based blogs do not discuss food as a daily task of making food for family members, but rather present it as a hobbyist practice. Interestingly, Cairns, Johnston, and Baumann (2010) also found in their study of thirty American "foodies," that the women describe the work of cooking for others "through ideals of care that prioritize the daily nourishment of the family" while the men "framed cooking as a leisure activity, even when they were also engaging in daily food preparation within the home” (p. 605). The male-run vegan websites, including Vegan Dad, include very few discussions of personal life, and instead focus on the technique of the recipe. Many of the male-run vegan websites also include few recipe posts. One website, named after and run by the vegan athlete and author Rich Roll (2016), has recipe posts that are all authored by a single individual named Julie Piatt. A Google search revealed that Julie Piatt is Rich Roll's wife. The search into vegan blogs for this study reveals initial findings that men are scarce in the vegan blogging community, and that, aside from Vegan Dad, cooking on male-run vegan blogs is often presented as an individualistic hobby or a boost to personal athleticism.

\section{Minimalist Baker}

Minimalist Baker has been running since 2012, but Dana, the primary author, has been involved in the blogging world since 2010. The goal of the blog is to share simple and easy recipes. Each of the recipes on the site is either made with less than 10 ingredients, made with only one bowl/pot, or takes 30 minutes or less to prepare (Shultz, n.d.). Furthermore, almost all of the recipes on the site are gluten free and vegan (Shultz, n.d.). Dana and her husband John say that they "don't subscribe to any one diet," but that their recipes are plant-based, and recipes that include honey, for example, always include a vegan substitute in parentheses. Their "About" (Shultz, n.d.) page says that Dana is lactose intolerant, and for that and other health reasons, both Dana and John eat mostly plant-based diets. 


\section{Oh She Glows}

The author of Oh She Glows, Angela, alternates between identifying as "vegan” or "plant-based" due to threatening responses from readers who argue that her practice isn't vegan enough (Liddon, 2015a). In the “About” page (Liddon, 2008), Angela lists, in order: health, animal welfare, and environment as her motivations for adopting a vegan diet. The goal of the website, she says, is to share "healthy, unprocessed, and animal-product free recipes that [she creates] to keep [herself] and [her] family inspired about tasty good-for-you food” (Liddon, 2008). She adds that her husband lost twenty pounds and lowered his high cholesterol without dieting or medication due to her "creating healthy plant-based recipes that would win over [her] husband's approval." She adds that since "Eric was a devout fast-food lover... [it] was a difficult task" (Liddon, 2008). Furthermore, she writes that "[her] goal is to inspire [the reader] to embrace more plant-based foods in [their] diet without feeling the least bit deprived" and that her "recipes are great for meat-eaters and picky kids too!” (Liddon, 2008).

\section{Vegan Dad}

Vegan Dad has no "About” page, and personal information available on the site is limited. Based on the few personal details shared, it can be determined that "Vegan Dad" is a history professor at an Ontario university (Vegan Dad, 2012), who has Crohn's disease (Vegan Dad, 2015). According to a post on giving up cheese (Vegan Dad, 2008a), "Vegan Dad” began the gradual transition to veganism after watching Super Size Me (Spurlock, 2004), and now practices veganism for health, animal rights, and environmental reasons. Most of “Vegan Dad's” posts involve cooking meals for his kids with an occasional mention of "Vegan Mom" (Vegan Dad, 2016). According to the blog archive, "Vegan Dad" has been blogging on this site since September 2007. The motto of his website is: "I only make one claim about my food: it’s vegan."

\section{Results}

In an analysis of the seventy-five blog posts and their comments, several major themes arise. This analysis considers them from three perspectives: gendered appetites, food type, and food labour. Discussions of gender appropriate food types on the blogs reveal that some vegan food items are described using gendered language, particularly meat alternative-based dishes; that men are often described as "carnivores" who are unwilling to eat vegetable-based meals; and that some recipes, especially meat alternative-based dishes, are promoted as suitable and enjoyable for men. This analysis will demonstrate that the needs and preferences of men are the primary focus of discussions in the blog posts, and that while practicing veganism provides an 
opportunity to transgress the food norms promoted by traditional masculinity, vegan food is largely discussed on these blogs in support of traditional gender ideologies.

\section{Even though it's vegan, it's still filling!}

On the blogs, there is a clear effort to promote vegan recipes as being satisfying in order to counter narratives that consider meatless meals to be lacking. Adjectives such as "hearty," "meaty," "satisfying," "huge," and "messy" are used to masculinize the meal, and to reassure the reader that these meals would satisfy even the "heartiest" appetites. Additionally, the blog authors highlight the recipes’ protein-content and ability to satisfy large appetites. These descriptive words are most often used in recipes for vegan meatballs, pulled pork, Sloppy Joes, taco meat, and burgers. For example, Dana describes her “Easy Grillable Veggie Burgers” recipe as "hearty, simple, flavorful, satisfying, crowd-pleasing, [and] tasty" (Shultz, 2016). In the discussion of the recipe, Dana adds: "Did I mention that each burger... has nearly 14 grams of protein?! Trust me, you're going to go home satisfied after eating one of these (especially when paired with a hearty salad, sweet potato wedges, or crispy baked matchstick fries)... Hearty enough to please meat-eaters and vegans alike!” (Shultz, 2016).

The author makes an effort to reassure the reader that even though the burger contains no meat, it still has a lot of protein, which traditional masculinity values for men's strength (Adams, 2015), and will be satisfying enough for meat-eaters, especially if paired with fries or a salad that is also "hearty." A commenter named Ellison (2016) agrees with Dana's claims, and writes: "This is one of the few veggie dishes I have made that did not leave me hungry an hour later." Additionally, a commenter named Debbie (2016) says that they and their husband enjoyed Minimalist Baker's recipe for "Vegan Sloppy Joes," and their husband, the "beanpole," who can "magically pack away lots of food," ate "2 sandwiches on hearty rolls," while Debbie only "ate one.” Debbie's (2016) comment not only points out that their husband approves of the meal, but also that he ate twice the amount that she did. Just as Lynch (2010) found on the health food blogs, Debbie (2016) compares their petite serving to their male partner's large serving and appetite.

Dana from Minimalist Baker also uses words that describe the large, generous, and potentially excessive features of this meal. As mentioned in the literature review, Cavazza et al. (2015) found that large portion size and rough presentation symbolize the masculinity of a dish in addition to the meaty food type. In Dana's instructions for the vegan pulled pork sandwich, she writes: "Place generous portions of slaw on the bottom buns, top with generous serving of BBQ jackfruit, and cashews. Serve with extra BBQ sauce! [emphasis added]” (Shultz, 2015). Angela uses similar language to describe how readers should eat her "Lentil-Walnut Tacos," writing that they should: "Stuff into face, make HUGE mess, repeat until you can't fit one more bite, craving conquered [emphasis original]” (Liddon, 2014). This type of language describing large portion sizes and aggressive consumption was only found on meat substitute-based recipes, 
effectively making them "safe" for men to eat without jeopardizing their sense of masculinity through consuming "feminine" vegetable-based foods.

\section{"Man Food List"}

"One thing he says he could not give up is an Italian beef sammich [sic] so I plan to take your recipe and try to Italian beef-it-up to try to get him to the right side of the force" Chigirl86 (2011)

There are specific recipes on the blogs that are recommended as "partner-friendly recipes" and others which have many comments suggesting that they are popular for pleasing male partners. Blog posts that specify whether or not the recipe is appropriate or enjoyed by specific genders identify dishes such as burgers and lunchmeat as particularly satisfying for men. One specific blog post by Oh She Glows (Liddon, 2016) is the primary source for discussions on maleappropriate vegan foods. The discussion, titled "omnivore-friendly recipes," arises from a question asked by a reader named Alyce, who writes: "My partner is a big meat eater and carb loader-I was wondering if you could let me know which recipes of yours you would recommend to try on him first to get him into it" (Liddon, 2016). Angela responds by saying that she is "all about" "partner-friendly recipes" and that if her husband Eric doesn't like a recipe that she makes, then "it doesn't get posted on [her] blog” (Liddon, 2016). Here, Angela heteronormatively uses the term "partner-friendly recipes" synonymously with the term "omnivore-friendly recipes" that she uses in the title of the post. Since the vast majority of commenters on Oh She Glows, as well as the other blogs, describe their partners to be men, this means that "partner-friendly" recipes are often catered towards men, and assumes that those men are omnivores. One commenter says they would add Angela's recipe for "Speedy Teriyaki Bowls" to the "Man Food List" since their "bf... managed to chomp away an entire bowl, and has requested the recipe AGAIN today [emphasis in original]" (Evelyn, 2016). The "partnerfriendly" recipes in this post are only discussed in respect to male partners; therefore the particular recipes that the commenters suggest are ones that they consider to be appropriate not just for cooking for their own partners, but for other people to make for their male partners as well.

\section{Carnivorous men need some convincing}

In the seventy-five blog posts, there are many commenters who describe how they are surprised that they convinced their partners to like a vegan dish, or divulge that they had to disguise the vegetables or legumes in a meal to get their male partners to eat it. Many of the readers write that even carnivorous men liked the vegan food they had made, and suggest that men's approval 
means the recipe was a success. The majority of these comments are made on recipes for Sloppy Joes, tacos, meatballs, burgers, crispy tofu stir-fry, and jackfruit “pulled pork."

On Oh She Glows' recipe for "Ultimate Green Taco Wraps with Lentil-Walnut Taco Meat,” Erica (2014) writes, “I’ve been looking for meat-free Mexican dishes that would satisfy my carnivore boyfriend” and a commenter named Rachel (2014) comments, "It's honestly one of the best things I've made... My husband and son tried it and loved the 'meat' and they are both committed carnivores.” On Minimalist Baker's recipe for "Sun-dried Tomato and Basil Meatballs,” Milla (2015) writes that “even [their] non-vegan husband couldn't stop eating them,” Rachael (2015) writes that, "even [their] carnivore boyfriend loved them,” and DanDan (2016) says that they "even got the 'carnivore’ to enjoy it!” Martha (2015) made Minimalist Baker's "BBQ Jackfruit Sandwiches” and writes: "although he is the carnivore of the family, [their husband] thought it was delicious!” And finally, Maddy (2015), who self-identifies as a vegetarian, made this recipe that "fooled" their "4 heavy meat-eating male" housemates into thinking it was pork. Maddy (2015) adds that one housemate "kept talking about how good his bbq 'pork' was.”

There are additional commenters who confess that their husbands were unaware that they were eating vegan food. Rosey (2014) comments on Minimalist Baker's recipe for "Simple Vegan Meatballs" that they have made the recipe twice and that their "carnivore husband likes it too" but "has no idea he is eating tempeh.” Ashley (2016) comments on Minimalist Baker's recipe for "Vegan Gluten Free Mac 'N' Cheese” that their husband "didn't even know it was vegan! :).” Jessica (2016) also writes that they made Minimalist Baker's “Refined Sugar Free Turtle Brownies" recipe for their husband and they both "LOVED [emphasis in original]" them, but their husband is "totally in the dark about them being black bean brownies, [and they] have no plans to tell him.” In these examples, the commenters choose not to disclose to their husbands that they were eating tempeh, dairy free macaroni and cheese, and legumes in their dessert.

The partners of men on these blogs comment that their boyfriends and husbands don't like vegan food, are surprised if they like vegan food, or disguise the vegan nature of the food they serve to men. Interestingly, the act of sneaking healthy food and vegetables into food is a technique espoused by Jessica Seinfeld (2007) in her cookbook Deceptively Delicious: Simple Secrets to Get Your Kids Eating Good Food. On the blogs this technique is used on adult men, rather than children, to get them to eat vegetables and other vegan food. For example, when Angela of Oh She Glows writes of how she "converted” Eric to liking Brussel sprouts by cooking them until they had a "meaty texture," to which she adds the disclaimer, "for a veggie, that is" (Liddon, 2015b). In addition to making sure vegan food is "manly" enough and satisfying to their male partners, commenters on the blogs describe the parental, caring labour they undertake to ensure that their husbands are eating healthy. 


\section{Cooking healthy food for men}

Among the plethora of examples where commenters exclaim that even the "meat-loving" men they have cooked for enjoyed the vegan recipe, there were only two examples where a commenter mentions whether or not their wife or girlfriend enjoyed a recipe, and only one example where a commenter mentions that their daughter liked the recipe (Michelle, 2015). Michellebee (2009) writes that their "Veg Life Partner" chose veggie meat over salami for her lunch and a commenter named Starkdoulos (2011) says that the recipe tasted just like ribs and that their wife was amazed. The remaining commenters on these blogs describe cooking for their male partners and the challenges of finding vegetable-based dishes that "carnivore" men like.

One of the main examples of this is in a post by Angela (Liddon, 2010) where she answers readers' questions about Eric's meat and dairy consumption. While Angela follows a vegan diet, Eric is an omnivore (Liddon, 2010). In response to when and how much meat Eric eats and if he is eating dairy, Angela (Liddon, 2010) responds: "He said he eats meat about 3 times a month. We keep frozen organic meat in the freezer when he buys it and when he gets a craving I will cook him some or he will BBQ a burger for himself. He enjoys a juicy beef burger now and then... He slowly cut cheese out of his diet after the doctor told him his LDL cholesterol was high a few years ago.”

This paragraph reveals information about gendered food and gender-appropriate food labour. Eric is an omnivore, and Angela says that he only eats meat three to four times per month. The words “cravings” and “juicy,” serve to reclaim Eric's masculinity, because while he cares more about what he is eating for his health, he still can’t fully resist his desires for juicy meat. Eric's reduction in meat and dairy consumption is motivated primarily by health concerns, and his continued consumption of these products when he "craves it," poses little threat to his masculinity (Johnson, 2011). Finally, Angela mentions that while Eric seldom eats animal products, and she herself runs a vegan blog, when Eric gets a craving for meat she "will cook him some, or he will BBQ a burger for himself.” Here we can see that not only will Angela, who is vegan, prepare meat for her husband, who could do so himself, but that if he makes himself meat, it will be over the fire of a grill. Consequently, Angela's (2010) description of her husband's meat eating practices mirror the findings of Nath (2011), who found that barbequing meat is considered to be a socially acceptable form of food labour performed by men, and Sobal (2005) who found that wives who do not eat meat are pressured to cook meat to satisfy their husbands.

The subsequent comments on this post all recount the same tales; partner after partner describing how they make healthy meals for their junk food-loving husbands and boyfriends. A commenter named Megan (2010) writes:

When I started dating my husband, he was a "junk food vegan.” His typical lunch was an order (or two) of french fries and breadsticks from our college cafeteria! After 8 years of his vegan diet, he decided he felt TOO restricted and wanted to add meat 
back into his diet- but he was craving junk food meat, like chicken nuggets and double cheeseburgers. Ugh. I think he's just got to get it out of his system after all the restriction! Fortunately, he will eat healthy, vegetable-centric dinners if I prepare them.

Megan describes the restriction in his diet, not as a lack of fruits, vegetables, or dairy, but a lack of meat. And while Megan's husband now eats meat, his diet still consists of junk food. However, he will eat vegetables if Megan prepares them for him. In this example meat is considered a necessary part of an "unrestricted” diet for Megan's husband, despite the lack of fruits and vegetables. Additionally, Megan is positioned as responsible for making healthy, "vegetable-centric" meals to care for their husband's health.

This type of emotional and care work was also found by Cairns et al. (2010) in their study of American "foodies." Many of the female foodies interviewed mention the importance of choosing and cooking food that is healthy for their children and spouses, while Cairns et al. (2010) note that "the theme of family health was notably absent among men [they] interviewed" (p. 605). In their study of families' rationales for women's unequal responsibility for food labour across three ethno-cultural groups in Canada, Beagan, Chapman, D’Sylva, and Bassett (2008) found that "male partners suggested that because women did most of the shopping and food preparation the healthfulness of the family diet was in their hands" (p. 662). Furthermore, they found that responsibility for family health is a way that women justify their over-involvement in household food work, and their duty as good partners and mothers (Beagan et al., 2008). The women argue that while they don't think food work is women's work, they “[had] to do all the foodwork or their families will eat nothing but 'junk”” (Beagan et al., 2008, p. 662).

\section{Room for alternative masculinities?}

The majority of discussion on these blog posts reproduce traditional masculine ideals such as: real men eat meat; men need meat to be strong and satisfy their hearty appetites; and men need to be convinced to eat vegetables. While the genders of the commenters are unknown, what is obvious is that the people participating in discussions on the vegan blogs are almost exclusively performing food labour to satisfy their male partners. Furthermore, there is no mention of a "Woman Food List" or of specific vegan recipes that are appropriate for women, since their vegan status pre-labels them as appropriate for female diets.

Perhaps it is for this reason that many of the studies mentioned in the literature review argue that men are hesitant to adopt a vegan diet, and the masculinity of those that do adopt a vegan diet must be reinforced with other qualities valued by traditional masculine ideals through acts "reclaiming of privilege lost” (Rogers, 2008, p. 296). For example, Coret (2014) describes instances where his gender has been policed by people that he knows for not being masculine because of his vegetarian diet, often being told that he "[eats] like a girl," and that he feels the need to compensate for his vegetarianism to gain the respect of his girlfriend's ex-military, 
football-loving father. While the evidence in the blog posts may overwhelmingly appear to support traditional gender ideals of masculine, meat-loving men and commenters performing the labour to care for the health of their male partners, perhaps there is passive subversion of traditional gender norms within these posts as well. While many of the posts have an overwhelming presence of commenters divulging that they perform these food tasks for men, and few commenters describing performing these food tasks for women or trans* partners, there are also many posts on the three blogs that have no gender signification for the food. Many comments have no reference to anyone of known gender, and may be written by a woman, man, or trans* individual making food for themselves.

Vegan Dad's blog stands out as a challenge to traditional gender norms. In some ways, Vegan Dad reproduces traditional ideals of masculinity by limiting the "diary" aspect of his posts, often substituting it for a technical discussion of the recipe, and by featuring few vegetable-based recipes. This is similar to the other male-run vegan food blogs that have few "diary" type discussions, and it reinforces the idea that male cooking focuses on skill and special events, rather than the caring and daily food work described by women who cook (Cairns et al., 2010). However, Vegan Dad does stand in opposition to most of the traditional masculine ideals discussed in this paper. He is the only blog author of the three who is primarily vegan for ethical reasons, which Johnson (2011) argues is a threat to traditional masculinity. He, moreover, describes making meals for his children and wife on the blog, and features posts on making kidfriendly foods and performing domestic tasks such as planning meals and cooking dried beans in bulk and preserving them. Additionally, out of the seventy-five blog posts, there is only one blatant challenge to traditional masculine ideals, and Vegan Dad writes it on his post for "Shaved Seitan BBQ Sandwich.” A commenter named Mark (2008) writes regarding the recipe that: "[they] must convince [their] wife to make this for [them] so [they] can take it to work and make a total fool of [themself].” Mark's (2008) comment implies that it is their wife's responsibility to make their lunches and that having a vegan BBQ sandwich at work would affectively "make a fool” of Mark. However, Vegan Dad (2008b) responds to Mark's comment by saying: "Mark, dudes are doing it for themselves in the kitchen these days!” Aside from Vegan Dad's explicit questioning of food labour as feminine work, the remaining discussions lack an awareness of how food type, appetites, and labour are gendered on the blogs.

\section{Conclusion}

While this paper presents an analysis of seventy-five vegan blog posts that feature many instances where traditional gender norms are reinforced, perhaps, like in the example of Vegan Dad, there are opportunities for vegan men and women to challenge these norms of what food is appropriate for certain genders, and whose responsibility it is to prepare it. However, the examples of motivation for veganism in this study are limited. I would therefore encourage future research in this area to evaluate how the motivations behind adopting a vegan diet 
influence how vegan food and its creation is perceived as a gendered, non-gendered, or gender subversive act. Just as Johnson (2011) argues that adopting a vegan diet for health reasons may not challenge, and can even serve to reinforce the ideals of traditional masculinity, a study investigating individuals that are explicitly vegan for ethical reasons may produce different results.

Discussions of gender appropriate food types on the blogs reveal that some vegan food items are described using gendered language, especially meat alternative based dishes; that men are often described as unwilling to eat vegetable-based meals; that some recipes, often meat alternative-based dishes, are promoted as suitable and enjoyable for men; and that "carnivorous" men appear to be the most valued measure of what constitutes a successful vegan recipe. In this cultural context of primarily white, middle-class, heterosexual, cis-gendered North American vegans, the same hegemonic gender norms are being reinforced through narratives of vegan food. However, because these ideals are socially constructed, and not permanent categories of reality, they can also be changed, redefined, ignored, or challenged. In the blog posts analyzed in this study there is evidence of both the reinforcement and challenging of traditional gender norms. Fundamentally, eliminating the consumption of animal products from one's diet challenges the patriarchal notion that meat is required for strong (male) bodies (Adams, 2015) and provides an opportunity for alternative practices. However, a vegan practice that removes animal products from a diet but espouses hyper-masculine motivations, gender appropriate food types, and male-serving food labour ultimately does not challenge traditional gender norms.

Acknowledgements: I would like to thank my supervisors, Dr. Tina Moffat and Dr. Shanti Morell-Hart in the Anthropology Department at McMaster University, for their support and guidance. I would also like to thank the reviewers' useful feedback and suggestion of including Jessica Seinfeld's cookbook, all my colleagues who provided support and ideas, and Nick Abrams for emotional support and editing.

\section{References}

Adams, C. (2015). The sexual politics of meat: A feminist-vegetarian critical theory $\left(20^{\text {th }}\right.$ Anniversary ed.). New York, NY: Bloomsbury Academic.

Alexa.com. (2016a). Site overview: minimalistbaker.com. Retrieved from http://www.alexa.com/siteinfo/minimalistbaker.com

Alexa.com. (2016b). Site overview: ohsheglows.com. Retrieved from http://www.alexa.com/siteinfo/ohsheglows.com

Ashley. (2016, April 2). The best vegan gluten free Mac 'n' Cheese [Web log comment]. Retrieved from http://minimalistbaker.com/best-vegan-gluten-free-mac-ncheese/\#comment-661956 
Beagan, B., Chapman, G. E., D’Sylva, A., \& Bassett, B. R. (2008). 'It's just easier for me to do it': Rationalizing the family division of foodwork. Sociology, 42(4), 653-671.

Boepple, L., \& Thompson, J. K. (2014). A content analysis of healthy living blogs: Evidence of content thematically consistent with dysfunctional eating attitudes and behaviors. International Journal of Eating Disorders, 47(4), 362-367.

Brady, J., \& Ventresca, M. (2014). “Officially A vegan now”: On meat and Renaissance masculinity in pro football. Food and Foodways, 22(4), 300-321.

Butler, J. (1988). Performative acts and gender constitution: An essay in phenomenology and feminist theory. Theatre Journal, 40(4), 519-531.

Cairns, K., Johnston, J., \& Baumann, S. (2010). Caring about food doing gender in the foodie kitchen. Gender \& Society, 24(5), 591-615.

Cavazza, N., Guidetti, M., \& Butera, F. (2015). Ingredients of gender-based stereotypes about food: Indirect influence of food type, portion size and presentation on gendered intentions to eat. Appetite, 91, 266-272.

Cherry, E. (2006). Veganism as a cultural movement: A relational approach. Social Movement Studies, 5(2), 155-170.

Chigirl68. (2011, November 8). Veggie lunch meat [Web log comment]. Retrieved from http://vegandad.blogspot.com/2008/06/veggie-lunchmeat.html?showComment $=1320789690831 \#$ c2196020117392923623

Coret, A. (2014, November 28). Men eat pizza, women eat salads. The Silhouette. Retrieved from https://www.thesil.ca/men-eat-pizza-women-eat-salads

DanDan. (2016, February 3). Sun-dried tomato and basil meatballs [Web log comment]. Retrieved from http://minimalistbaker.com/vegan-sun-dried-tomato-basilmeatballs/\#comment-648285

Dejmanee, T. (2016). "Food porn” as postfeminist play: Digital femininity and the female body on food blogs. Television \& New Media, 17(5), 429-448.

Devine, C. M., Connors, M., Bisogni, C. A., \& Sobal, J. (1998). Life course influences on fruit and vegetable trajectories: Qualitative analysis of food choices. Journal of Nutrition Education and Behavior, 30, 361-370.

Debbie. (2016, April 7). Vegan Sloppy Joes [Web log comment]. Retrieved from http://minimalistbaker.com/vegan-sloppy-joes/\#comment-663265

Ellison. (2016, April 13). Easy grillable veggie burgers [Web log comment]. Retrieved from http://minimalistbaker.com/easy-grillable-veggie-burgers/comment-page-2/\#comment$\underline{663874}$ 
Erica. (2014, June 17). Ultimate green lentil-walnut taco wraps [Web log comment]. Retrieved from http://ohsheglows.com/2014/06/17/ultimate-green-taco-wraps-with-lentil-walnuttaco-meat-vegan-gluten-free/\#comment-905589

Evelyn. (2016, April 17). Friday FAQs: Storing sour cream, omnivore-friendly recipes, lentils, banana swaps, and more! [Web log comment]. Retrieved from http://ohsheglows.com/2016/04/15/friday-faqs-storing-sour-cream-omnivore-friendlyrecipes-lentils-banana-swaps-and-more/\#comment-1783207

Gelfer, J. (2013). Meat and masculinity in men’s ministries. The Journal of Men's Studies, 21(1), 78-91.

Geller, P. L. (2009). Identity and difference: complicating gender in archaeology. Annual Review of Anthropology, 38, 65-81.

Greenebaum, J., \& Dexter, B. (2017). Vegan men and hybrid masculinity. Journal of Gender Studies, 1-12.

Hookway, N. (2008). Entering the blogosphere': Some strategies for using blogs in social research. Qualitative Research, 8(1), 91-113.

Hopkins, J. (2012). History of the Manwich. Foodimentary. [Web log comment]. Retrieved from http://foodimentary.com/2012/03/18/history-of-the-manwich/

Irvine, B. (2015). Vegetarian masculinities: How discourses of normative masculinity are challenged and (re)produced through food consumption. The New Birmingham Review, 1(2).

Johnson, J. A. (2011). Hegans: An examination of the emerging male vegan. Theses Dissertations, and Other Capstone Projects, (Paper 124).

Jessica. (2016, April 30). Refined sugar free turtle brownies [Web log comment]. Retrieved from http://minimalistbaker.com/refined-sugar-free-black-bean-brownies/\#comment$\underline{665832}$

Liddon, A. (2008, October 28). About. Retrieved from http://ohsheglows.com/about/

Liddon, A. (2010, August 3). Verbose Tuesday [Web log post]. Retrieved from http://ohsheglows.com/2010/08/03/verbose-tuesday/

Liddon, A. (2014, June 17). Ultimate green lentil-walnut taco wraps [Web log comment]. Retrieved from http://ohsheglows.com/2014/06/17/ultimate-green-taco-wraps-with-lentilwalnut-taco-meat-vegan-gluten-free/

Liddon, A. (2015a, March 23). Will you raise your daughter a vegan? My answer may surprise you [Web log post]. Retrieved from http://ohsheglows.com/2015/03/23/will-you-raiseyour-daughter-a-vegan-my-answer-may-surprise-you/ 
Liddon, A. (2015b, November 21). Mouth-watering crispy brussels sprouts (plus 7 ways to flavour them!) [Web log comment]. Retrieved from http://ohsheglows.com/2015/11/21/mouth-watering-crispy-brussels-sprouts-plus-7-waysto-flavour-them/

Liddon, A. (2016, April 15). Friday FAQs: Storing sour cream, omnivore-friendly recipes, lentils, banana swaps, and more! [Web log comment]. Retrieved from http://ohsheglows.com/2016/04/15/friday-faqs-storing-sour-cream-omnivore-friendlyrecipes-lentils-banana-swaps-and-more/

Lutz, A. (2015). How Hungry-Man’s supersized frozen meals are defying every industry trend. Business Insider. Retrieved 4 December 2015, http://www.businessinsider.com/hungrymans-sales-are-soaring-2015-3

Lynch, M. (2010). Healthy habits or damaging diets: An exploratory study of a food blogging community. Ecology of food and nutrition, 49(4), 316-335.

Maddy. (2015, July 21). BBQ jackfruit sandwich with avocado slaw [Web log comment]. Retrieved from http://minimalistbaker.com/bbq-jackfruit-sandwiches-with-avocadoslaw/\#comment-555063

Mark. (2008, June 20). Shaved seitan BBQ sandwich [Web log comment]. Retrieved from http://vegandad.blogspot.com/2008/06/shaved-seitanbbqsandwich.html?showComment=1213936680000\#c3215906956847919214

Martha. (2015, November 28). BBQ jackfruit sandwich with avocado slaw [Web log comment]. Retrieved from http://minimalistbaker.com/bbq-jackfruit-sandwiches-withavocado-slaw/\#comment-631884

Maurer, D. (2002). Vegetarianism: Movement or moment? Philadelphia, PA: Temple UP.

Megan. (2010, August 3). Verbose Tuesday [Web log comment]. Retrieved from http://ohsheglows.com/2010/08/03/verbose-tuesday/\#comment-94022

Michelle. (2015, November 29) BBQ jackfruit sandwich with avocado slaw [Web log comment]. Retrieved from http://minimalistbaker.com/bbq-jackfruit-sandwiches-withavocado-slaw/\#comment-673867

Michellebee. (2009, December 7). Veggie lunch meat [Web log comment]. Retrieved from http:/vegandad.blogspot.com/2008/06/veggie-lunchmeat.html?showComment=1260164392383\#c4924914894869036291

Milla. (2015, September 30). Sun-dried tomato and basil meatballs [Web log comment]. Retrieved from http://minimalistbaker.com/vegan-sun-dried-tomato-basilmeatballs/\#comment-597758 
Minson, J. A., \& Monin, B. (2012). Do-gooder derogation disparaging morally motivated minorities to defuse anticipated reproach. Social Psychological and Personality Science, 3(2), 200-207.

Nath, J. (2011). Gendered fare? A qualitative investigation of alternative food and masculinities. Journal of Sociology, 1-18.

Potts, A., \& Parry, J. (2010). Vegan sexuality: Challenging heteronormative masculinity through meat-free sex. Feminism \& Psychology, 20(1), 53-72.

Rachael. (2015, October 2). Sun-dried Tomato and Basil Meatballs [Web log comment]. Retrieved from http://minimalistbaker.com/vegan-sun-dried-tomato-basil$\underline{\text { meatballs/\#comment-598668 }}$

Rachel. (2014, June 23). Ultimate green lentil-walnut taco wraps [Web log comment]. Retrieved from http://ohsheglows.com/2014/06/17/ultimate-green-taco-wraps-with-lentilwalnut-taco-meat-vegan-gluten-free/\#comment-927486

Rich Roll. (2016). Retrieved from http://www.richroll.com

Rogers, R. A. (2008). Beasts, burgers, and hummers: Meat and the crisis of masculinity in contemporary television advertisements. Environmental Communication, (2)3, 281-301.

Roos, G., Prättälä, R., \& Koski, K. (2001). Men, masculinity and food: interviews with Finnish carpenters and engineers. Appetite, 37(1), 47-56.

Rosey. (2014, December 1). Simple vegan meatballs [Web log comment]. Retrieved from http://minimalistbaker.com/simple-vegan-meatballs/comment-page-1/\#comment-445076

Rothgerber, H. (2013). Real men don’t eat (vegetable) quiche: Masculinity and the justification of meat consumption. Psychology of Men \& Masculinity, 14(4), 363.

Rozin, P., Hormes, J. M., Faith, M. S., \& Wansink, B. (2012). Is meat male? A quantitative multimethod framework to establish metaphoric relationships. Journal of Consumer Research, 39(3), 629-643.

Ruby, M. B. \& Heine, S. J. (2011). Meat, morals, and masculinity. Appetite, 56, 447-450.

Salvio, P. M. (2012). Dishing it out: Food blogs and post-feminist domesticity. Gastronomica, 12(3), 31.

Seinfeld, J. (2007). Deceptively delicious: Simple secrets to get your kids eating good food. HarperCollins.

Shultz, D. (n.d.). About. Retrieved from http://minimalistbaker.com/about/

Shultz, D. (2015, March 17). BBQ jackfruit sandwich with avocado slaw [Web log comment]. Retrieved from http://minimalistbaker.com/bbq-jackfruit-sandwiches-with-avocado-slaw/ 
Shultz, D. (2016, February 3). Easy grillable veggie burgers [Web log comment]. Retrieved from http://minimalistbaker.com/easy-grillable-veggie-burgers/

Snee, H. (2010). Using blog analysis. Realities Toolkit \#10. Retrieved from http://eprints.ncrm.ac.uk/1321/2/10-toolkit-blog-analysis.pdf

Sobal, J. (2005). Men, meat and marriage: Models of masculinity. Food and Foodways, 13, 13558.

Spurlock, M. (Producer \& Director). (2004). Super Size Me [Documentary]. United States: Samuel Goldwyn Films and Roadside Attractions.

Starkdoulos. (2011, June 3). Veggie Lunch Meat [Web log comment]. Retrieved from http://vegandad.blogspot.com/2008/06/veggie-lunch$\underline{\text { meat.html?showComment }=1307128824507 \# c 6419972053069565506}$

Stein, R. I., \& Nemeroff, C. J. (1995). Moral overtones of food: Judgments of others based on what they eat. Personality and Social Psychology Bulletin, 21(5), 480-490.

Sumpter, K. C. (2015). Masculinity and meat consumption: An analysis through the theoretical lens of hegemonic masculinity and alternative masculinity theories. Sociology Compass, 9(2), 104-114.

The Vegan Stoner. (2016). Retrieved from http://theveganstoner.blogspot.ca

The Vegan Zombie. (2016). Retrieved from http://theveganzombie.com

Thomas, M. A. (2016). Are vegans the same as vegetarians? The effect of diet on perceptions of masculinity. Appetite, 97, 79-86.

Thug Kitchen. (2016). Retrieved from http://www.thugkitchen.com

Turner, K., Ferguson, S., Craig, J., Jeffries, A., \& Beaton, S. (2013). Gendered identity negotiations through food consumption. Young Consumers, 14(3), 280-288.

Vegan Black Metal Chef. (2016). Retrieved from http://veganblackmetalchef.com

Vegan Dad. (2008a, May 7). On the giving up of the cheese [Web log comment]. Retrieved from http:/vegandad.blogspot.ca/2008/05/on-giving-up-of-cheese.html

Vegan Dad. (2008b, June 20). Shaved seitan BBQ sandwich [Web log comment]. Retrieved from http://vegandad.blogspot.com/2008/06/shaved-seitan-bbqsandwich.html?showComment=1213964220000\#c8264723917369009324

Vegan Dad. (2012, December 10). Gluten-free yeast donuts [Web log comment]. Retrieved from http://vegandad.blogspot.ca/2012/12/gluten-free-yeast-donuts.html 
Vegan Dad. (2015, November 24). Savour stuffing rolls [Web log post]. Retrieved from http://vegandad.blogspot.ca/2015/11/savoury-stuffing-rolls.html

Vegan Dad. (2016, May 3). Lemon meringue pie [Web log comment]. Retrieved from http://vegandad.blogspot.ca/2016/05/lemon-meringue-pie.html

West, C., \& Zimmerman, D. H. (1987). Doing gender. Gender \& Society, 1, 125-151.

Wright, L. (2015). The vegan studies project. Athens, GA: University of Georgia Press. 